\title{
Application of the Technique of "Mobile Skin and Soft Tissue Window" in Single Segment Lumbar Interbody Fusion
}

\author{
Jing Wang*, Min Chen, Jiang Du \\ Department of Orthopedics, the First Affiliated Hospital of Jinan University, Guangzhou, China \\ Email address: \\ twjing@jnu.edu.cn (Jing Wang) \\ ${ }^{*}$ Corresponding author
}

\section{To cite this article:}

Jing Wang, Min Chen, Jiang Du. Application of the Technique of "Mobile Skin and Soft Tissue Window" in Single Segment Lumbar Interbody Fusion. Journal of Surgery. Vol. 4, No. 2, 2016, pp. 45-48. doi: 10.11648/j.js.20160402.19

Received: April 11, 2016; Accepted: April 22, 2016; Published: May 12, 2016

\begin{abstract}
To investigate the surgical techniques and short-term clinical effects of minimally invasive lumbar interbody fusion in the treatment of lumbar degenerative diseases, 43 patients who underwent minimally invasive posterior lumbar interbody fusion from January 2012 to September 2014 were retrospectively reviewed. The lesion was located by C- arm fluoroscopy during the operation. The working areas for placing pedicle screw, fusion and decompression were well exposed by the technique of "mobile skin and soft tissue window". The operation time, intraoperative blood loss, length of incision, blood drainage and complication after operation were recorded. Oswestry disability index (ODI) and visual analogue scale (VAS) of pre-operation, 7 days, 1, 3 and 12 months postoperatively were evaluated. 37 patients were followed up for an average of $15.2 \pm 4.7$ months. Intraoperative blood loss was $175.1 \pm 71.8 \mathrm{ml}$; operation time was $129.0 \pm 12.0 \mathrm{~min}$; length of incision was $5.4 \pm 0.3 \mathrm{~cm}$ and postoperative blood drainage was $116.5 \pm 66.0 \mathrm{ml}$. Postoperative lumbar and leg VAS and ODI scores were significantly decreased, comparing with that of pre-operation $(\mathrm{P}<0.05)$. Lumbar VAS score was $6.6 \pm 0.8$ before operation and $0.7 \pm 0.6$ at 12-month follow-up. Leg VAS score was $7.0 \pm 0.1$ before operation and $0.6 \pm 0.5$ at 12 -month follow-up. Average ODI percent was $68.6 \% \pm 5.4 \%$ before operation and $6.2 \% \pm 1.6 \%$ at 12 -month follow-up. There were no internal fixation loose and fracture, and the radiographic findings were consistent with the standard of the lumbar interbody fusion at the last follow-up. In the current study, the minimally invasive treatment concept and the technology of "mobile skin and soft tissue window" are applied to the traditional posterior lumbar interbody fusion surgery. This modified method can not only obtain good vision without special instruments, but can also significantly reduce the skin incision and muscle tissue dissection, get less surgical trauma and better functional recovery, achieving a satisfactory clinical effect for single segment lumbar degenerative disease.
\end{abstract}

Keywords: Spinal Fusion, Lumbar Vertebrae, Minimally Invasive Surgical Procedures

\section{Introduction}

Spinal fusion is a standard operation to reconstruct the spinal stability, which has been widely used for the treatment of many lumbar degenerative diseases [1]. Traditional posterior fusion surgery has the property of clear field of vision, large operation space, full and complete decompression, but has the disadvantages of wide range release of paraspinal muscles, big surgical trauma and more blood loss, which would adversely affect the functional recovery of older patients [2, 3]. To overcome these disadvantages, a variety of minimally invasive spine techniques are applied with good clinical outcomes [4, 5]. However, the minimally invasive techniques currently used in spinal fusion have problems like small operative field, limited operating space, high risk ratio of spinal injury and steep learning curve $[6,7]$. Besides, the radiation exposure of both patients and operators is much higher than traditional operation $[8,9]$. Thus we need to combine the advantages of minimally invasive and traditional techniques to reduce trauma during operation. Recent years, we applied minimally invasive techniques to traditional posterior lumbar fusion, 
using the "mobile skin and soft tissue window" technique as the core operating strategy. Only positions that are closely related to the operation are exposed, with same exposure field as traditional method but significantly reduced skin incision length, less paraspinal muscle tissue stretch, less trauma and bleeding. Patients using this technique resulted in good functional recovery.

\section{Materials and Methods}

\subsection{Subject Selection}

43 patients of lumbar degenerative disease who underwent minimally invasive posterior lumbar interbody fusion from January 2012 to September 2014 were retrospectively included. 25 cases of male, 18 cases of female, of average age $52.3 \pm 17.0$ years old (ranging from 42 to 89 ). The main clinical manifestations were lumbago merged with unilateral or bilateral lower extremity pain, accompanied by numbness or intermittent claudication. 3 months later no significant side effect after resting, medication and other conservative treatment. There were 19 cases of lumbar disc herniation, 15 cases of lumbar spinal stenosis and 9 cases of lumbar spondylolisthesis. Operated segments: 2 cases of L3/4, 29 cases of L4/5 and 12 cases of L5/S1. Pre-operative oswestry disability index (ODI) was $68.6 \% \pm 5.4 \%$, lumbago visual analogue scale (VAS) score was $6.6 \pm 0.8$, and leg VAS score was $7.0 \pm 0.1$. Patients were taken usual X-rays of lumbar lateral position, excessive flexion position and oblique position, lumbar $\mathrm{CT}$ reconstruction and $\mathrm{MR}$ were taken to confirm the pathological changes with clinical symptoms.

\subsection{Surgical Methods}

After intubation anesthesia, patients were placed in a prone position, with a soft pillow under iliac crest on both sides, floating belly. Patients were scanned by C-arm X-ray machine to confirm the lesion segments and make marks. Use the mark as a center to cut the skin, about $5 \mathrm{~cm}$. Strictly strip along one side of the spinous process and lamina bone surface to facet outer edge. To expose by laminectomy retractors, place the locating pin, use the $\mathrm{C}$ - arm X-ray machine for visualization and placing pedicle screw. After extending the incision $1 \mathrm{~cm}$ upward or downward to expose the adjacent facet joint, then the pedicle screw was inserted. Use yarn block to stop bleeding and remove laminectomy retractors. Use the same method to implant the contralateral pedicle screw. Use the transforaminal lumbar interbody fusion (TLIF) for decompression [10], discectomy and interbody cage fusion surgery. Apply anti-biotics for 3 days, with mannitol, dexamethasone for 3 days, and mecobalamin for 7 days. Drainage tubes were removed after 24-48 h. 2 days post operation, do straight leg raising and lumbar back muscle exercise; 5-7 days post operation, get out of bed wearing waist for exercise.

\subsection{Clinical Follow-up and Evaluation Methods}

Telephone follow-up or clinic referral were taken 7 days, 1 , 3, 6 and 12 month after the treatment, recording the pain VAS, ODI values. 6 months later, X-rays and CT examinations were taken to check the fusion. The fusion standard: trabecular bone connecting the upper and lower endplate; X-ray images show no photic zone; flexion and extension fusion segments without displacement.

\subsection{Statistical Analysis}

SPSS 18.0 (PASW, Statistics, IBM) were used to analyze the data. Data were presented as $\bar{x} \pm s$. Comparison of values of VAS and ODI before and after treatment were analyzed by repeated measures ANOVA. Comparison of values within different time points were analyzed by Bonferroni t-test. $\mathrm{P}<0.05$ was considered significant.

\section{Results}

The surgeries were all went smoothly. Intraoperative blood loss was $90-300 \mathrm{ml}(175.1 \pm 71.8 \mathrm{ml})$; operation time was 103-150 min (129.0 $\pm 12.0 \mathrm{~min})$; incision length 5.1-6.0 cm (5.4 $\pm 0.3 \mathrm{~cm})$; postoperative drainage was $80-240 \mathrm{ml}(116.5 \pm 66.0$ $\mathrm{ml}) .2$ cases of lumbar spinal stenosis showed severe spinal adhesions, with a small range of dural tear during incision. Postoperative drainage was clean, drainage tube was removed $24 \mathrm{~h}$ later, no other complications happened. All patients showed no wound infection, nonunion or other complications. No broken or loose of the screws were found during the follow-up. 37 cases were followed up, average time was 13-25 months (15.2 \pm 4.7 months). Pain after surgery were obviously relieved (Table 1). Postoperative lumbar and leg VAS and ODI scores were significantly comparing with that of pre-operation $(\mathrm{P}<0.05)$. Lumbar VAS score was $6.6 \pm 0.8$ before operation and $0.7 \pm 0.6$ at 12 -month follow-up. Leg VAS score was $7.0 \pm$ 0.1 before operation and $0.6 \pm 0.5$ at 12 -month follow-up. Average ODI percent was $68.6 \% \pm 5.4 \%$ before operation and $6.2 \% \pm 1.6 \%$ at 12 -month follow-up. 6 months after operation, the images indicated the 32 cases showed bone fusion and reached the standard of bone fusion at the last follow-up month. A typical case was shown in Figure 1.

Table 1. ODI and VAS change before and after operation ( $\bar{x} \pm s$ ).

\begin{tabular}{lllllll}
\hline & $\begin{array}{l}\text { Before } \\
\text { operation }\end{array}$ & $\begin{array}{l}\text { 7 day after } \\
\text { operation }\end{array}$ & $\begin{array}{l}\text { 1 month after } \\
\text { operation }\end{array}$ & $\begin{array}{l}\text { 3 month after } \\
\text { operation }\end{array}$ & $\begin{array}{l}\text { 12 month after } \\
\text { operation }\end{array}$ & $\begin{array}{l}\text { F Value } \\
\text { P Value }\end{array}$ \\
\hline Lumbar VAS & $6.6 \pm 0.8$ & $1.5 \pm 0.6$ & $1.2 \pm 0.6$ & $1.0 \pm 0.6$ & $0.7 \pm 0.6$ & \\
Leg VAS & $7.0 \pm 0.1$ & $1.0 \pm 0.3$ & $0.9 \pm 0.4$ & $0.8 \pm 0.6$ & $0.6 \pm 0.5$ & $\mathrm{~F}=541.33$ \\
ODI (\%) & $68.6 \pm 5.4$ & $9.1 \pm 2.6$ & $7.7 \pm 2.2$ & $6.8 \pm 1.8$ & 6.000 & $\mathrm{~F}=1.6$ \\
\hline
\end{tabular}

There is significant difference between ODI and VAS before and after operation, $\mathrm{P}<0.05$. 


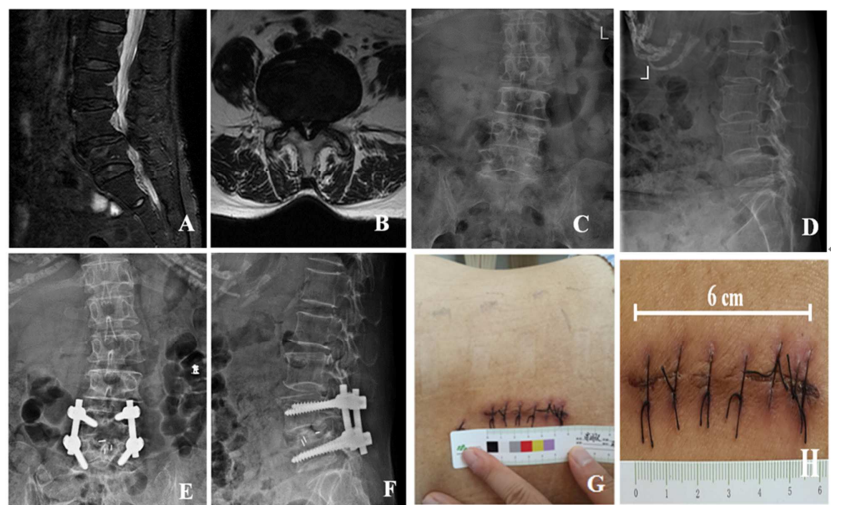

Figure 1. A typical case. A, B: preoperative MRI of the lumbar spine show $L_{4}$ ${ }_{1} 5$ intervertebral disc herniation, ligamentum flavum thickening, $L_{4 / 5}$ spinal canal stenosis; $C, D$ : preoperative $X$-ray show $L_{4}$ vertebral degenerative spondylolisthesis I; E, F: postoperative lumbar X-ray, the place of internal fixation device is good; G, H: skin incision length is $6 \mathrm{~cm}$, skin incision heal and take out stitches in 12th day after operation.

\section{Discussion}

Minimally invasive technique is developing fast recently, becoming the important direction of spine surgery. Minimally invasive spinal surgery combines itself with traditional spinal surgery to completely relieve the compression of spinal cord and nerve roots, to reduce damages to the original bone and soft tissue structures and to restrict the biomechanical stability. Actually, minimally invasive techniques cover any surgical techniques that cause less invasive injuries, not limited to endoscopic surgery, small incisions through expansion or fixed channel or other microsurgery $[11,12]$. Nowadays, spinal minimally invasive technique develops from simple lumbar discectomy to complex spinal fusion and internal fixation. Spinal minimally invasive technique often combines spinal endoscopy, percutaneous spinal surgery and channel technique. But the application of spinal minimally invasive technique encounters many problems, including the high standard of surgical equipment and instruments, long and steep learning curve $[7,8]$, increased risk of small and limited operation vision and space, and especially difficult operation when applying bilateral decompression with another necessary incision [13]. Balancing the convenience and safety of traditional open surgery and minimized tissue trauma of minimally invasive technique would make the ideal surgical method. Based on the traditional posterior lumbar fusion procedure, we improved the small incision and minimally invasive protocol and resulted in good outcomes.

Our improvement changes the traditional concept, applying the philosophy of minimally invasive procedure to every steps of traditional open operation and optimized the application of surgical skills and instruments of traditional posterior spinal surgery. The results are obvious, compared to traditional posterior surgery, our improved method has the following advantages: small incision, less muscle stripping, less trauma and rapid recovery; all the operations are finished with direct vision, of high security; a series of operations, such as insert bilateral pedicle screw, decompression and restoration within a single incision are completed of high convenience; low threshold to apply, no steep learning curve and easy to popularize. Because of less trauma, less blood loss and less postoperative drainage, this improved surgical method has obvious advantages comparing to those traditional posterior lumbar internal fixation [14]. This is especially beneficial for the elderly. Meanwhile, this surgery largely shortens the exposure time to X-rays, for both patients and doctors, which has positive meanings to professional protections [9]. However, there are also some disadvantages such as the limited incision cut, comparing to muscle gap approach by minimally channels. But comparing with the steep learning curve of minimally invasive channel surgeries which demand the very rich experience in open surgery $[7,8,15]$, our improved method is much more approachable. The technique of "mobile skin and soft tissue window" in single segment lumbar interbody fusion belongs to minimally invasive technique and can lay a solid foundation for the further development for endoscopic and channel surgeries.

\section{References}

[1] Kanemura, T., et al., The maturation of grafted bone after posterior lumbar interbody fusion with an interbody carbon cage: a prospective five-year study. J Bone Joint Surg Br, 2011. 93(12): p. 1638-45.

[2] Kim, D. Y., et al., Comparison of multifidus muscle atrophy and trunk extension muscle strength: percutaneous versus open pedicle screw fixation. Spine (Phila Pa 1976), 2005. 30(1): p. 123-9.

[3] Barnes, B., et al., Threaded cortical bone dowels for lumbar interbody fusion: over 1-year mean follow up in 28 patients. $\mathrm{J}$ Neurosurg, 2001. 95(1 Suppl): p. 1-4.

[4] Yoo, J. S., et al., Paraspinal muscle changes of unilateral multilevel minimally invasive transforaminal interbody fusion. J Orthop Surg Res, 2014. 9: p. 130.

[5] Huang, C. J., et al., [Analysis of intermediate and long term clinical effects on discectomy with diskoscope]. Zhongguo $\mathrm{Gu}$ Shang, 2009. 22(4): p. 251-3.

[6] Hoogland, T., et al., Transforaminal posterolateral endoscopic discectomy with or without the combination of a low-dose chymopapain: a prospective randomized study in 280 consecutive cases. Spine (Phila Pa 1976), 2006. 31(24): p. E890-7.

[7] Hirano, Y., et al., Percutaneous endoscopic lumbar discectomy - early clinical experience. Neurol Med Chir (Tokyo), 2012. 52(9): p. 625-30.

[8] Kim, C. W., et al., The current state of minimally invasive spine surgery. Instr Course Lect, 2011. 60: p. 353-70.

[9] Erken, H. Y., et al., Can radiation exposure to the surgeon be reduced with freehand pedicle screw fixation technique in pediatric spinal deformity correction? A prospective multicenter study. Spine (Phila Pa 1976), 2014. 39(6): p. 521-5. 
[10] Xia, X. L., et al., Mast Quadrant-assisted minimally invasive modified transforaminal lumbar interbody fusion: single incision versus double incision. Chin Med J (Engl), 2015. 128(7): p. 871-6.

[11] McAnany, S. J., et al., Open Versus Minimally Invasive Fixation Techniques for Thoracolumbar Trauma: A Meta-Analysis. Global Spine J, 2016. 6(2): p. 186-94.

[12] Uribe, J. S., S. L. Myhre, and J. A. Youssef, Preservation or Restoration of Segmental and Regional Spinal Lordosis Using Minimally Invasive Interbody Fusion Techniques in Degenerative Lumbar Conditions: a Literature Review. Spine (Phila Pa 1976), 2016.
[13] Cho, J. Y., S. H. Lee, and H. Y. Lee, Prevention of development of postoperative dysesthesia in transforaminal percutaneous endoscopic lumbar discectomy for intracanalicular lumbar disc herniation: floating retraction technique. Minim Invasive Neurosurg, 2011. 54(5-6): p. 214-8.

[14] Ghahreman, A., et al., Minimal access versus open posterior lumbar interbody fusion in the treatment of spondylolisthesis. Neurosurgery, 2010. 66(2): p. 296-304; discussion 304.

[15] Smith, N., et al., Systematic review of microendoscopic discectomy for lumbar disc herniation. Eur Spine J, 2013. 22(11): p. 2458-65. 